\title{
Facebook Addiction and its Association with Academic Performance
}

\author{
*Nida Tabassum Khan \\ Department of Biotechnology, Baluchistan University of Information Technology Engineering and Management Sciences, Pakistan
}

Received: March 12, 2018; Published: April 11, 2018

*Corresponding author: Nida Tabassum Khan, Department of Biotechnology, Faculty of Life Sciences and Informatics, Baluchistan University of Information Technology Engineering and Management Sciences,(BUITEMS), Quetta, Pakistan, Tel: 03368164903;

Email: nidatabassumkhan@yahoo.com

\begin{abstract}
Social network sites such as face book provides an online user friendly facility to the people to share their personal or professional profiles by connecting with other users with whom they share a common interest. Facebook addiction interfered with addicts' academic/ professional performance and their social lives as a large number of students spend most of their time on Facebook which affects the academic execution of those students. The study revealed high (51\%) prevalence of face book addiction among undergraduates at BUITEMS and also a strong correlation was determined between face book addiction and academic performance of student.
\end{abstract}

Keywords: Bergen Face Book Addiction Scale; Facebook Addiction; Social Capital; Psychological Disorder

\section{Introduction}

Social network sites such as Facebook provides an online user friendly facility to the people to share their personal or professional profiles by connecting with other users with whom they share a common interest [1]. Facebook enabled different communities/ groups of people to stay connected [2] by instantly messaging and navigating [3]. Social networks in specific face book have provided ways for social engagement as a potent tool for depicting an individual's personality through his/her public profile [4]. A study revealed that $82 \%$ of young adults and $55 \%$ adolescents were regular Facebook users [5]. As it is obvious with an increased and free access to these social sites, there will be an elevated number of people who engage in such activities on daily basis [6]. Purpose of Facebook use varies from person to person which mostly includes entertainment, maintaining relationships, meeting new people, social events and media creation [7,8]. Among mounting explosion of social network sites probability of social network addiction is also very common and is now being characterized as a psychological disorder worldwide [9]. Increasing plea of social networks could potentially be a cause for concern, especially taken in account the amount of time spends online by the young adults and adolescents [10]. From a psychological standpoint, it may be probable that Facebook addiction of a person's is influenced by his or her personal life issues such as negligence in personal life, mental preoccupation, mood modifying experiences, tolerance etc as these issues were prominent in some people who were identified as
Facebook addicts [11,12]. Evidences from previous researches have shown that Facebook addiction interfered with addicts' academic/ professional performance and their social lives [13]. A large number of students spend most of their time on Facebook [14]. According to a research it revealed that the time deployed on Facebook did influence the academic execution of those students [15]. Therefore the main purpose of this study was to determine the prevalence of face book addiction and also to analyze the factors influencing an individual's face book addiction. Relationship between face book addiction and academic performance of student was also evaluated during this study.

\section{Materials and Methods}

A total of 100 undergraduate students were selected from different department at BUITEMS. To fall within the selection criteria, every respondent must be a regular Facebook user. This analytical study was conducted using the BFAS scale (Bergen face book addiction scale) (Andreassen et al., 2012) [16]. Demographic information (age, gender etc) and academic information (CGPA and current semester) and time spent on Facebook (minutes per day) was also considered.

\section{BFAS Scale Scoring:}

a) 0 to 19: Low

b) $20-49$ : Moderate 
c) 50 - 79: High -possible Facebook

d) 80 - 100: Extremely high -Facebook addict

e) Statistical analysis of the data was done by means of Microsoft excel

\section{Results}

Out of 100 participants, $59 \%$ were females and $41 \%$ were males as depicted in (Figures $1 \& 2$ ). Represents the face book addiction factors in both the genders. Frequency of Facebook account access everyday by University Undergraduates is given in (Figures 3 \& 4). Reveals the current cgpa of the selected participants Incidence of face book addiction is given in (Figure 5).

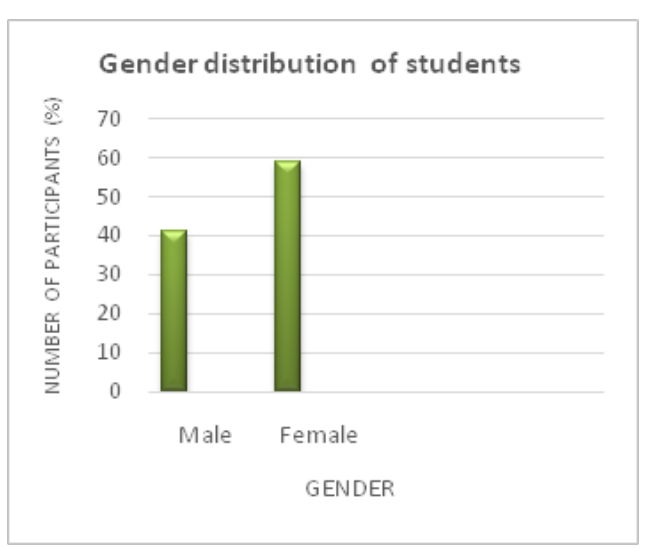

Figure 1: Sex distribution.

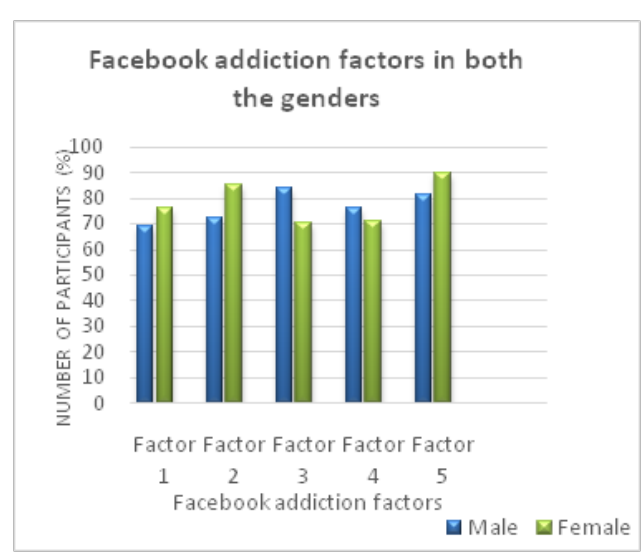

Figure 2: Prevalence of face book addiction factors.

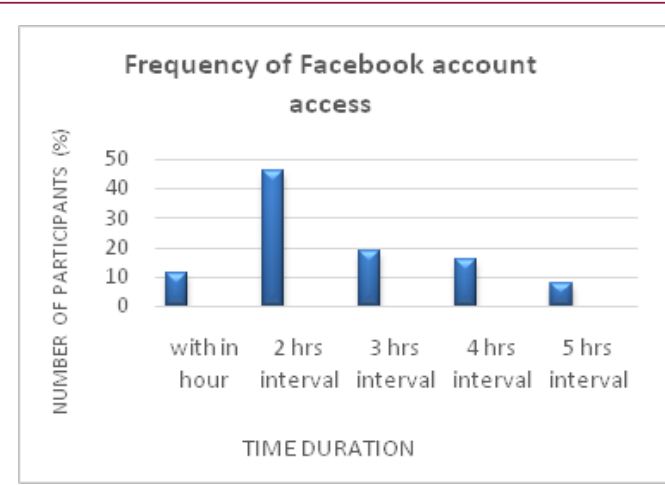

Figure 3: Frequency of Facebook account access.
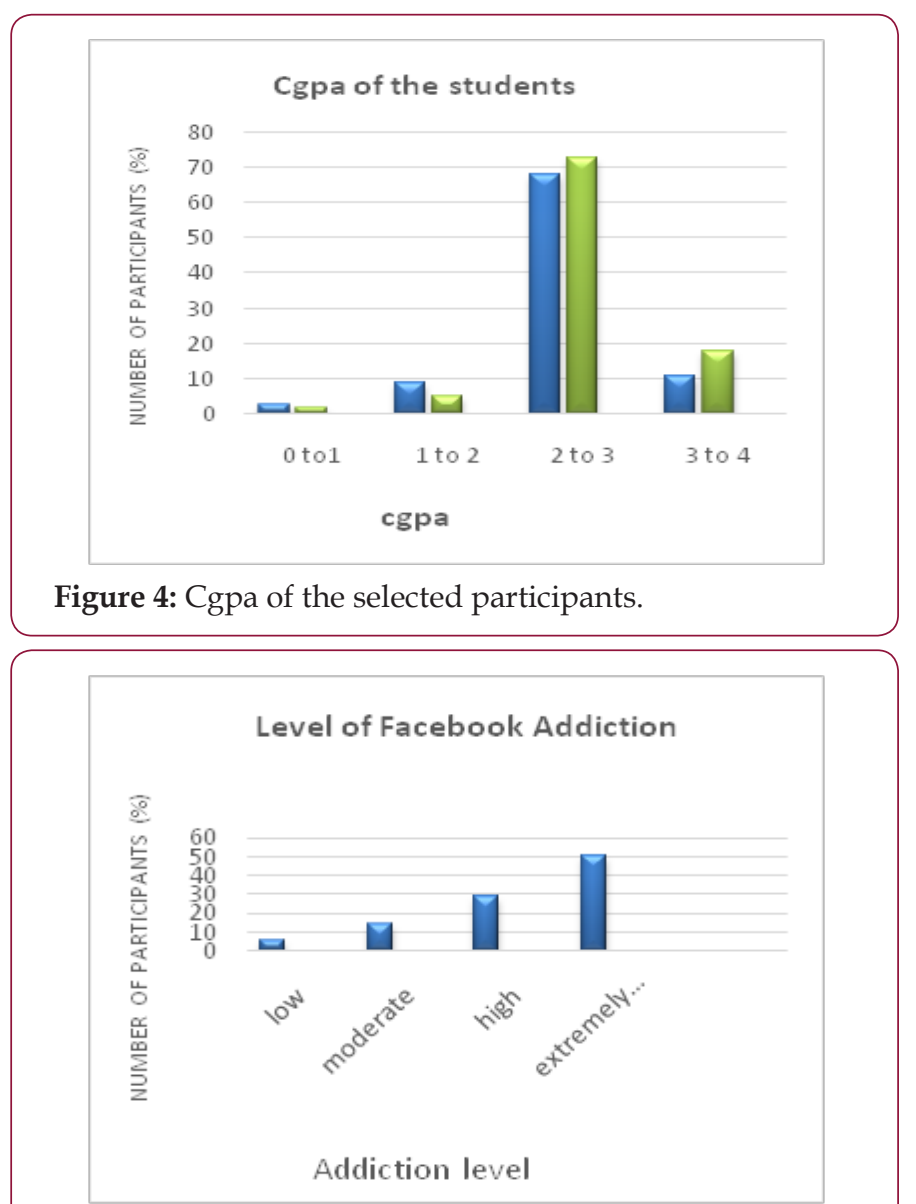

Figure 5: Level of face book addiction.

\section{Discussion}

This study revealed that undergraduates were active Facebook users. Availability of internet on phones, laptops, tablets etc has greatly increased the access of students to face book [16,17]. As further revealed by the findings of this study, $46 \%$ of the subjects of this study access their Facebook account every passing two hour of their wakening moment, $19 \%$ do so at least three hour interval while $16.0 \%$ do so at least three hour interval as indicated in Figure 3. Further analysis showed that only $51 \%$ were high addiction users, $14 \%$ were moderate users and $29 \%$ were possible face book addicts as given in Figure 5. It is a known fact that technological advancements comes with its negative side, most especially when misused or abused [18]. Increased level of international connectivity and social interaction leads to addiction as our obtained result revealed that both sexes have the same likelihood of succumbing to the abusive or addictive use of Facebook [19].

Majority of students at BUITEMS are from financially stable backgrounds where internet access and facilities are not an issue. Therefore at BUITEMS, undergraduates Facebook addiction is prevalent as indicated by the conducted study. Therefore there is a need to consider this social network addiction as a serious disorder and measures should be devising to minimize Facebook use. This research also measured the effect of Facebook addiction on the academic performance. BFAS results revealed that extraversion was found to be highly significant among undergraduates as 
indicated in Figure 2 suggesting that people who are extroverts and outgoing spend a lot of time using and thinking about Facebook [20]. Furthermore, our results depicted a positive relationship between face book addiction and both neuroticism and openness to experience. It is quite true that users who are not emotionally stable tend to be more engaged in such activities in order to get rid of their problems [21].

Students who invest more time on Facebook spend less time finishing scholarly work as indicated in our study that high Facebook users usually obtained low cgpa in their semester exams as Facebook is not widely used for learning purposes [22]. Constrains of this study were that exact measurement of Facebook utilization should be taken, sample size was limited which may have resulted in the inability to collect a large pool of people with varying personalities. Based on this study it is important to characterize this addiction as a serious disorder and counseling or other ways should be devised to minimize Facebook use.

\section{Conclusion}

Since the number of Facebook users is escalating in which a greater proportion is of students and undergraduates. Thus there is an elevated probability for those users to become Facebook addicts. Therefore there is a growing concern about such users obtaining low cgpa due to excessive Facebook use.

\section{References}

1. Ellison NB, Steinfield C, Lampe C (2007) The benefits of Facebook "friends:" Social capital and college students' use of online social network sites. Journal of Computer-Mediated Communication 12(4): 1143-1168.

2. Acquisti A, Gross R (2006) Imagined communities: Awareness, information sharing, and privacy on the Facebook. International workshop on privacy enhancing technologies p: 36-58

3. Pempek TA, Yermolayeva YA, Calvert SL (2009) College students' social networking experiences on Facebook. Journal of applied developmental psychology 30(3): 227-238.

4. Ross C, Orr ES, Sisic M, Arseneault JM, Simmering MG, et al. (2009) Personality and motivations associated with Facebook use. Computers in human behavior 25(2): 578-586.

5. Tong ST, Van Der Heide B, Lang well L, Walther JB (2008) Too much of a good thing? The relationship between number of friends and interpersonal impressions on Facebook. Journal of Computer-Mediated Communication 13(3): 531-549.

6. Atkinson NL, Saperstein SL, Pleis J (2009) Using the internet for healthrelated activities: findings from a national probability sample. Journal of medical Internet research 11(1).
7. Tosun LP (2012) Motives for Facebook use and expressing "true self" on the Internet. Computers in Human Behavior 28(4): 1510-1517.

8. Sheldon P (2008) Student favourite: Facebook and motives for its use. South western Mass Communication Journal 23(2): 39-53.

9. Griffiths MD (2012) Facebook addiction: concerns, criticism, and recommendations-a response to Andreessen and colleagues. Psychological Reports 110(2): 518-520.

10. Zaremohzzabieh Z, Samah BA, Omar SZ, Bolong J, Kamarudin NA (2014) Addictive Facebook use among university students. arXiv preprint arXiv $10(6)$.

11. Ehrenberg A, Juckes S, White KM, Walsh SP (2008) Personality and selfesteem as predictors of young people's technology use. Cyberpsychology \& behavior 11(6): 739-741.

12. Hong FY, Huang DH, Lin HY, Chiu SL (2014) Analysis of the psychological traits, Facebook usage, and Facebook addiction model of Taiwanese university students. Telematics and Informatics 31(4): 597-606.

13. Boogart V, Robert M (2006) Uncovering the social impacts of Facebook on a college campus (Doctoral dissertation, Kansas State University).

14. Abdulahi A, Samadi B, Gharleghi B (2014) A study on the negative effects of social networking sites such as facebook among asia pacific university scholars in Malaysia. International Journal of Business and Social Science 5(10):133-145.

15. Negussie N, Ketema G (2014) Relationship between Facebook Practice and Academic Performance of University Students. Asian Journal of Humanities and Social Sciences 2(2).

16. Andreassen CS, Torsheim T, Brunborg GS, Pallesen S (2012) Development of a Facebook addiction scale. Psychological reports 110(2): 501-517.

17. Kim J, La Rose R, Peng W (2009) Loneliness as the cause and the effect of problematic Internet use: The relationship between Internet use and psychological well-being Cyber Psychology \& Behavior 12(4): 451-455.

18. Kandell JJ (1998) Internet addiction on campus: The vulnerability of college students. Cyberpsychology \& behavior 1(1): 11-17.

19. Cao F, Su L (2007) Internet addiction among Chinese adolescents: prevalence and psychological features. Child: care, health and development 33(3): 275-281.

20. Har baugh ER (2010) The effect of personality styles (level of introversion-extroversion) on social media use. The Elon Journal of Undergraduate Research in Communications 1(2): 70-86.

21. Wilson K, Fornasier S, White KM (2010) Psychological predictors of young adults' use of social networking sites. Cyberpsychology, behavior, and social networking 13(2): 173-177.

22. Bedassa F (2014) Impact of Facebook Usage on Students Academic Performance.

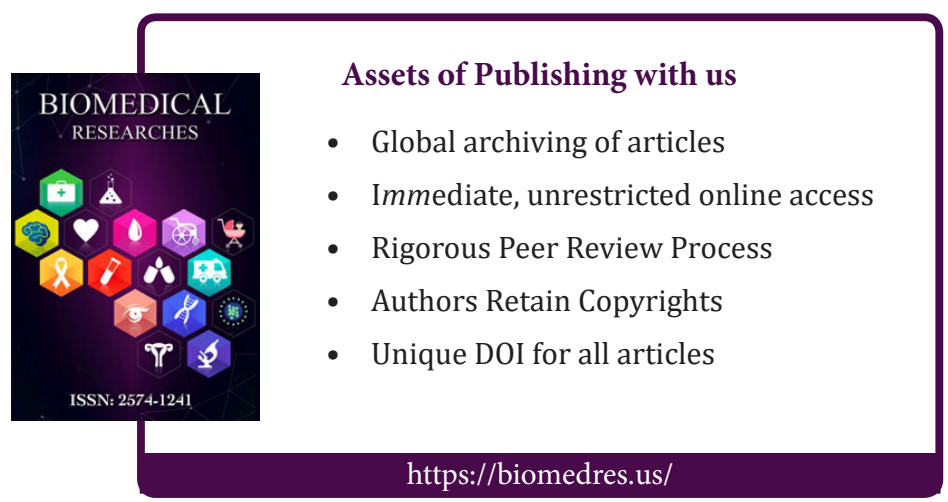

